\section{Commentary: Spinal cord ischemia: It's the anatomy, stupid}

\author{
Robert B. Hawkins, MD, MSc, and \\ J. Hunter Mehaffey, MD, MSc
}

The complication rate after thoracoabdominal aortic aneurysm repair has improved over the previous decades, in part because of a decline in spinal cord injury. ${ }^{1}$ Adjuncts such as cerebrospinal fluid drainage, hybrid approaches, circulatory support, permissive hypothermia, and segmental artery reimplantation are increasingly used. However, spinal cord ischemia remains a devastating complication, at a rate of $11 \%$ in a recent large study. ${ }^{2}$ Efforts continue to further reduce the morbidity and costs associated with paralysis. In this month's issue of the Journal, von Aspern and colleagues ${ }^{3}$ present an excellent analysis of how to optimize near-infrared spectrometry (NIRS) as an additional tool to detect and avoid ischemia.

This study used a porcine model of spinal cord ischemia and reperfusion, via repetitive aortic crossclamping. The NIRS electrodes detected tissue oxygenation levels of the collateral network with no difference at the high thoracic level (T1-T6) and suppression below this level with the most pronounced decreases in the lumbar region. These measurements were then correlated with microsphere perfusion measurements. Although NIRS measurements remained suppressed, microsphere measurements demonstrated increased perfusion toward the end of the ischemic time, a compensatory change worth further investigation.

To paraphrase James Carville, it's the anatomy, stupid! Previous work by Etz and colleagues ${ }^{4}$ demonstrated about $75 \%$ of segmental arteries give rise to an anterior spinal artery that supplies the intraspinal collateral network. However, segmental arteries also communicate with a large network in the paravertebral tissues and paraspinal muscles

\footnotetext{
From the Division of Thoracic and Cardiovascular Surgery, University of Virginia, Charlottesville, Va.

Disclosures: The authors reported no conflicts of interest.

The Journal policy requires editors and reviewers to disclose conflicts of interest and to decline handling or reviewing manuscripts for which they may have a conflict of interest. The editors and reviewers of this article have no conflicts of interest.

Received for publication Aug 19, 2020; revisions received Aug 19, 2020; accepted for publication Aug 20, 2020;

Address for reprints: Robert B. Hawkins, MD, MSc, Division of Thoracic and Cardiovascular Surgery, University of Virginia, P.O. Box 800679, Charlottesville, VA 22908 (E-mail: rbh6x@virginia.edu).

J Thorac Cardiovasc Surg 2022;164:e17-8

$0022-5223 / \$ 36.00$

Copyright (c) 2020 by The American Association for Thoracic Surgery

https://doi.org/10.1016/j.jtcvs.2020.08.060
}

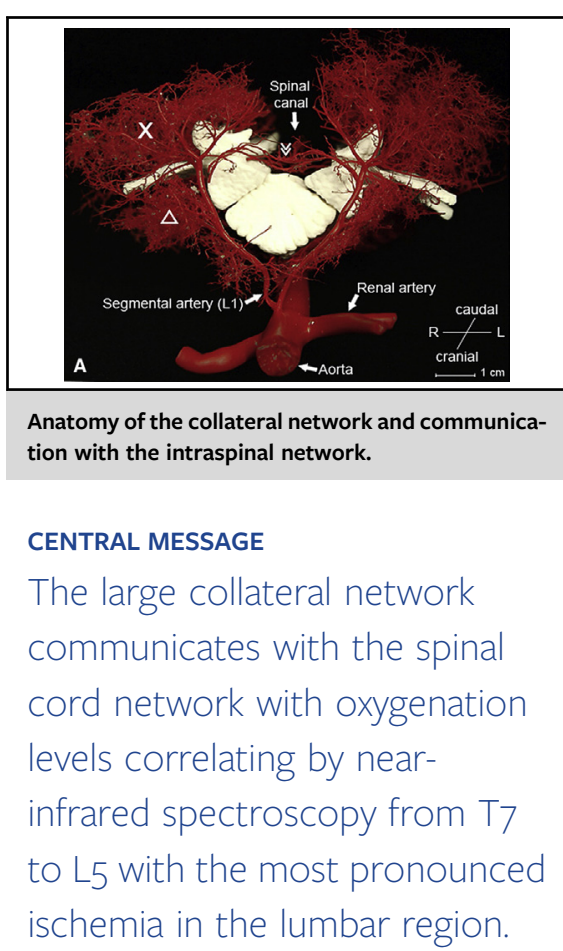

(the collateral network; Figure 1). The paraspinal collateral network is vastly larger than the anterior spinal artery/ epidural arcade. This collateral network communicates with the intraspinal network, and the authors have shown here that paraspinal placement of NIRS correlates with

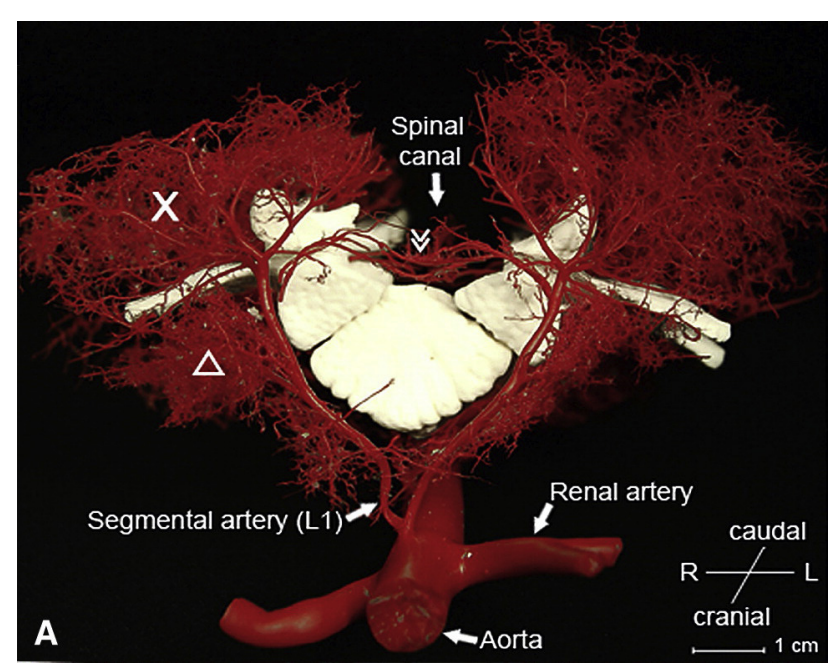

FIGURE 1. Anatomy of the collateral network, with $X$ designating vasculature of the paraspinous muscles, the triangle is the iliopsoas muscle, and the double arrow is the anterior spinal artery. Reprinted from Etz and colleagues. 
and detects spinal cord ischemia. However, the internal thoracic arteries (when still present) likely provide too much collateral flow to make high thoracic NIRS routinely useful. The application of mid-thoracic to lumbar NIRS for central nervous system monitoring during thoracoabdominal aortic aneurysm repair is an anatomically and now physiologically supported adjunct in the ever-evolving quest to eliminate spinal cord ischemia. Clinical comparisons with motor-evoked and somatosensory-evoked potentials are warranted.

\section{References}

1. Hawkins RB, Mehaffey JH, Narahari AK, Jain A, Ghanta RK, Kron IL, et al. Improved outcomes and value in staged hybrid extent II thoracoabdominal aortic aneurysm repair. J Vasc Surg. 2017;66:1357-63.

2. Coselli JS, Green SY, Price MD, Zhang QZ, Preventza O, de la Cruz KI, et al. Spinal cord deficit after 1114 extent II open thoracoabdominal aortic aneurysm repairs. J Thorac Cardiov Sur. 2020;159:1-13.

3. von Aspern K, Haunschild J, Khachatryan Z, Simoniuk U, Ossmann S, Borger MA, et al. Mapping the collateral network: optimal near-infrared spectroscopy optode placement. J Thorac Cardiovasc Surg. 2022;164:e3-15.

4. Etz CD, Kari FA, Mueller CS, Silovitz D, Brenner RM, Lin HM, et al. The collateral network concept: a reassessment of the anatomy of spinal cord perfusion. J Thorac Cardiovasc Surg. 2011;141:1020-8.
See Article page e3.

\section{Commentary: Noninvasive monitoring and spinal cord injury: The path from benchtop to bedside}

\author{
Edward D. Percy, MD, and Ashraf A. Sabe, MD
}

Despite advances in our understanding of pathophysiology and improvement in surgical techniques, spinal cord injury (SCI) remains the most devastating complication after extensive aortic repair involving the descending aorta. Rates of SCI have remained variable, between $2.9 \%$ and $16 \%$, and without significant overall improvement in recent years. ${ }^{1}$ The pathophysiology of SCI is related primarily to interruption of blood flow to the spinal cord in the absence of sufficient collateral network $(\mathrm{CN})$ flow.

Although the optimal approach to spinal cord protection is debated, the core principles are minimizing ischemic and reperfusion injury coupled with advanced monitoring techniques. $^{2}$ The use of near-infrared spectroscopy (NIRS) to measure blood oxygen saturation in the paraspinous muscles (theoretically an indirect indication of spinal cord oxygenation) is a promising noninvasive adjunct. This

From the Division of Cardiac Surgery, Department of Surgery, Brigham and Women's Hospital, Harvard Medical School, Boston, Mass.

Disclosures: The authors reported no conflicts of interest.

The Journal policy requires editors and reviewers to disclose conflicts of interest and to decline handling or reviewing manuscripts for which they may have a conflict of interest. The editors and reviewers of this article have no conflicts of interest.

Received for publication Aug 10, 2020; revisions received Aug 10, 2020; accepted for publication Nov 5, 2020;

Address for reprints: Ashraf A. Sabe, MD, Division of Cardiac Surgery, Brigham and Women's Hospital, 75 Francis St, Boston, MA 02115 (E-mail: asabe@partners. org).

J Thorac Cardiovasc Surg 2022;164:e18-9

0022-5223/\$0.00

Published by Elsevier Inc. on behalf of The American Association for Thoracic Surgery

https://doi.org/10.1016/j.jtcvs.2020.11.017

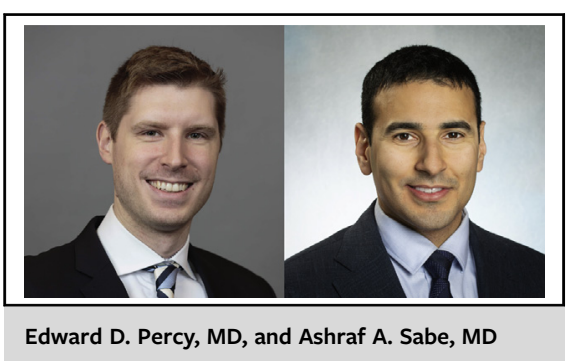

CENTRAL MESSAGE

Several techniques are on the

horizon for improving spinal

outcomes in aortic repair;

however, monitoring collateral

networks through near-infrared

spectroscopy is one of the most

promising options.

technology has been widely studied and applied in a variety of clinical settings, albeit with limited conclusive data, including monitoring plastic surgery flap perfusion, cerebral saturation monitoring in cardiovascular cases, and lower limb perfusion with extracorporeal membrane oxygenation (ECMO). ${ }^{3}$ The first reports of NIRS monitoring in human aortic repair were published in 2011; however, to date, no published experiments have examined the utility of NIRS monitoring of the entire paraspinous CN. ${ }^{4}$

In this edition of the Journal, von Aspern and colleagues present their findings of full paraspinous $\mathrm{CN}$ monitoring in a large animal model. ${ }^{5}$ By testing periods of aortic clamping in 10 juvenile pigs, the authors validated their method by 